\title{
Performance reprodutiva de leitoas submetidas à inseminação artificial pós-cervical
}

\author{
[Reproductive performance of gilts submitted to post-cervical artificial insemination] \\ E.M. Ternus ${ }^{1}$, A.R. Vanz $^{1}$, P.E. Lesskiu ${ }^{2}$, G.M. Preis ${ }^{1}$, L. Serafini ${ }^{1}$, W. Consoni ${ }^{1}$ \\ S.D. Traverso ${ }^{1}$, J. Cristani ${ }^{1}$ \\ ${ }^{1}$ Centro de Ciências Agroveterinárias - CAV - Universidade do Estado de Santa Catarina - UDESC - Lages, SC \\ ${ }^{2}$ BRF- Lucas do Rio Verde MT
}

\begin{abstract}
RESUMO
O objetivo deste trabalho foi avaliar o desempenho reprodutivo de nulíparas submetidas à inseminação artificial pós-cervical (IAPC) comparada à inseminação artificial tradicional (IAT). Foram avaliados ocorrência de sangramento, ocorrência de refluxo, dificuldade no transpasse da cérvix e total de células refluídas até 30 minutos após inseminação. Fêmeas submetidas à IAPC $(n=279)$ foram inseminadas com doses de $1,5 \times 10^{9}$ diluídas em $45 \mathrm{~mL}$, e fêmeas submetidas à IAT (n=273) inseminadas com doses de 2,5 x $10^{9}$ em 80mL. O transpasse da cérvix foi possível em 91,04\% (254/279) das leitoas. A dificuldade no transpasse foi de 41,58\% (116/279), não comprometendo o desempenho reprodutivo ( $\mathrm{P}>0,05)$. Presença de sangramento não afetou a taxa de parto nem o número de leitões nascidos para ambos os tratamentos $(\mathrm{P}>0,05)$. O percentual de espermatozoides presentes no refluxo foi maior na IAT, não sendo observada diferença no tamanho de leitegada de acordo com o percentual de espermatozoides no refluxo $(P>0,05)$ e no número de leitões nascidos totais $(11,63$ e 11,81) entre os tratamentos IAT e IAPC, respectivamente. Pode-se realizar IAPC em leitoas sem causar redução no desempenho, utilizando-se doses com 1,5 x $10^{9}$ células espermáticas.
\end{abstract}

Palavras-chave: fêmeas nulíparas, inseminação pós-cervical, inseminação tradicional, desempenho reprodutivo

\begin{abstract}
The objective of this study was to evaluate the reproductive performance of gilts subjected to postcervical artificial insemination (PCAI) compared to traditional artificial insemination (TAI). We also evaluated the degree of difficulty in bypassing the cervix, time required to perform the insemination, presence of bleeding after insemination, semen backflow, as well as the volume and the total reflow cells 30 minutes after insemination. Gilts submitted to PCAI $(n=279)$ were inseminated with $45 \mathrm{~mL}$ doses of $1.5 \times 10^{9}$ sperm cells and the ones submitted to TAI $(n=273)$ were inseminated with $80 \mathrm{~mL}$ doses with $2.5 \times 10^{9}$ cells. The bypassing of the cervix was possible in 91.04\% (254/279) of gilts. The difficulty bypassing the cervix in at least one of the gilt's PCAI procedures happened with $41.58 \%$ (116/279) of the females, but it did not affect reproductive performance $(P>0.05)$. The presence of bleeding after insemination did not affect the farrowing rate and total number of piglets born for both treatments $(P>0.05)$. The average time needed to carry out the PCAI was 1.47 minutes and the TAI was 4.04 minutes. The percentage of sperm present in the reflux was higher in TAI than the PCAI, but no correlation was found between litter size and the percentage of sperm in reflux $(P>0.05)$ and the total number of piglets born (11.63 and 11.81) between TAI and PCAI treatments, respectively. Thus, it is possible to perform the post-cervical artificial insemination in gilts without causing a reduction in reproductive performance, using doses with a concentration of $1.5 \times 10^{9}$ sperm cells.
\end{abstract}

Keywords: Nulliparous sows, post-cervical insemination, traditional insemination, reproductive performance

Recebido em 9 de outubro de 2016

Aceito em 10 de outubro de 2016

E-mail: eduardo.ternus@brf-br.com 


\section{INTRODUÇÃO}

A suinocultura industrial é uma atividade de grande desafio econômico. A superação das tradicionais oscilações sazonais de produtividade e a sanidade não são suficientes para garantir o sucesso da operação, pois, além de exigir excelência em resultados, a suinocultura necessita constante criatividade e adequação de técnicas, objetivando maximizar resultados (Brandt, 2008).

Quando se fala em busca de novas tecnologias e redução nos custos de produção, a inseminação artificial (IA) em suínos é uma das biotécnicas que mais apresentou avanços nos últimos anos. Introduzida no Brasil a partir de 1975, teve uma rápida expansão, passando de $2 \%$ do plantel submetido à IA na década de 90 (Scheid, 1991) para $27 \%$ no ano de 2000, correspondendo a $51 \%$ das coberturas realizadas em granjas tecnificadas (Wentz et al., 2000). Atualmente, estima-se que mais de $95 \%$ da suinocultura tecnificada utiliza a IA.

Na IA com deposição cervical, tradicionalmente a dose inseminante contém de dois a quatro bilhões de espermatozoides, em volume de 80 a $100 \mathrm{~mL}$, que podem ser armazenados por até três dias à temperatura de $15^{\circ} \mathrm{C}$ a $18^{\circ} \mathrm{C}$ (Martinez et al., 2001). Novas estratégias têm sido desenvolvidas para melhorar os resultados empregando-se técnicas que visam à deposição do sêmen mais próximo ao local da fertilização, utilizando, assim, menor volume e número de espermatozoides que o habitual (HernandezCaravaca et al., 2012).

O principal objetivo da IA está relacionado à otimização da utilização dos machos reprodutores, fazendo com que o uso dos ejaculados seja maximizado, trazendo, dessa forma, uma redução de custos consideráveis para a central de inseminação (Sonderman, 2016), sem que ocorra uma redução na eficiência reprodutiva e produtiva do plantel (Sbardella et al., 2014).

Hancock (1959), visando encontrar o número mínimo de espermatozoides por dose, descreveu uma técnica não cirúrgica para a deposição do sêmen no útero, porém somente muito tempo depois essa técnica foi aperfeiçoada. A validação de sua aplicação a campo foi de extrema importância devido aos benefícios econômicos que a redução do número de espermatozoides em mais de $50 \%$ e a redução do volume de diluente utilizado podem trazer (Dallanora et al., 2004), sem reduzir o índice de fecundidade (Levis et al., 2001). A redução da concentração espermática por dose resulta em um maior número de doses produzidas por macho (Sonderman, 2016), o que maximiza o uso dos machos geneticamente superiores, transmitindo mais rapidamente $\mathrm{o}$ ganho genético no rebanho (Bortolozzo et al., 2008).

Um sistema comercial que utiliza doses de 1,2 bilhão de espermatozoides (IAPC) em vez dos três bilhões de espermatozoides empregados em uma dose tradicional (IAT) permite que o produtor use $40 \%$ menos machos, o que possibilita a ele utilizar somente os de melhor valor genético, melhorando o índex genético do sistema.

As nulíparas ainda são pouco exploradas em relação à IAPC, as quais assumem um papel de destaque, representando o maior percentual no grupo de parição (16 a 18\%), sendo responsáveis por aproximadamente $13 \%$ dos leitões nascidos (Bortolozzo et al., 1999). Logo, há uma real necessidade de se intensificarem estudos nessa categoria de fêmeas para se alcançar um maior volume de fêmeas inseminadas pela IAPC e, consequentemente, reduzir o número de células espermáticas/fêmea/ano (Sbardella et al., 2014). $\mathrm{Na}$ IAPC em nulíparas, são poucos os relatos na literatura, e trabalhos a campo apresentam uma taxa de transpasse da cérvix baixa, o que inviabiliza o uso dessa técnica na rotina diária da granja.

Objetivou-se, com este estudo, avaliar a técnica de inseminação artificial pós-cervical (IAPC) em nulíparas e, para tanto, analisaram-se a taxa de sucesso no transpasse da cérvix e o desempenho reprodutivo das leitoas inseminadas com a IAPC.

\section{MATERIAL E MÉTODOS}

Todos os procedimentos do experimento foram conduzidos seguindo os preceitos de bem-estar animal e submetidos ao Comitê de Ética em Experimentação Animal (Cetea) do Centro de Ciências Agroveterinárias CAV - Udesc, protocolo $\mathrm{N}^{\mathrm{O}}$ 01.50.14. O trabalho foi realizado em uma granja comercial, em sistema de 
produção de leitoas, quarto sítio, com capacidade de alojamento de 1000 animais, localizada no meio-oeste de Santa Catarina (latitude: 2654'44,84', e longitude: 5148'05,94',), no período de abril a outubro de 2015. Foram utilizadas 560 fêmeas nulíparas da genética Hiper-Suíno $^{\circledR}$ (Landrace X Large White), divididas em dois grupos: grupo 1 - inseminação artificial pós-cervical (IAPC) e grupo 2 inseminação artificial tradicional (IAT). Foram realizadas 280 coberturas por grupo, (80 coberturas semanais, sendo 40 para cada tratamento, totalizando sete semanas de coberturas).

As leitoas eram oriundas das granjas multiplicadoras de matrizes da empresa Brasil Foods S/A (BRF), situadas no oeste de Santa Catarina (latitude: 26 52'11,83' e e longitude: $\left.52^{\circ} 18^{\prime} 07,51^{\prime \prime}\right)$. Após desembarcadas, eram conduzidas ao galpão de recepção, onde eram alojadas em baias coletivas com 12 fêmeas por baia, com área de 1,5 fêmea $/ \mathrm{m}^{2}$. A água foi fornecida à vontade e o arraçoamento seguia as exigências nutricionais dos animais segundo Rostagno et al. (2005) sendo as dietas e o manejo de arraçoamento idênticos para ambos os grupos.

O diagnóstico de cio foi realizado duas vezes ao dia (oito e 16 horas), utilizando-se o reflexo de tolerância ao macho na presença do homem (pressão no dorso). Duas semanas antes do cio seguinte, as leitoas eram conduzidas para outra instalação, onde eram alojadas em celas individuais $(0,55 \times 2,2 \mathrm{~m})$. $\mathrm{Na}$ manifestação do segundo cio, as leitoas eram encaminhadas para cobertura, com distribuição randômica nos diferentes grupos de inseminação. As leitoas eram pesadas individualmente e encaminhadas ao galpão de gestação, alojadas em celas individuais de $0,55 \times 2,2 \mathrm{~m}$, onde eram inseminadas.

As doses utilizadas foram feitas em homospermia, coletadas de 10 machos doadores da linhagem comercial Agroceres PIC ${ }^{\circledR} 425$ Elite (Agroceres PIC, Patos de Minas, MG, Brasil). Foi realizada avaliação espermática nos machos antes do início do experimento, sendo selecionados aqueles com percentual de patologia espermática inferior a $20 \%$. Os machos foram coletados uma vez por semana, de forma semiautomatizada (Manequim Equittec ${ }^{\circledR}$, Marau, RS, Brasil), pelo mesmo funcionário, e seus ejaculados analisados de forma computadorizada por meio do sistema CASA (Sperm Vision $3.7^{\circledR}$ Minitub, Tiefenbach, Alemanha). Posteriormente, os ejaculados foram diluídos com Androstar ${ }^{\circledR}$ Plus (Minitub, Tiefenbach, Alemanha), de forma automática, pelo SmartDispenser ${ }^{\circledR} \quad$ (Minitub, Tiefenbach, Alemanha), e as doses envazadas, de forma automática, pela GTB1000 ${ }^{\circledR}$ (IMV Technologies Group, França). Somente foram utilizados ejaculados com motilidade total superior a $80 \%$. Todas as doses foram produzidas em "split sample". As doses utilizadas na IAT continham $2,5 \times 10^{9}$ células espermáticas em $80 \mathrm{~mL}$, e as doses utilizadas na IAPC continham $1,5 \times 10^{9}$ células espermáticas em $45 \mathrm{~mL}$. As doses de sêmen foram armazenadas a $15-18^{\circ} \mathrm{C}$ e com tempo de estocagem máximo de 72 horas.

Cinco meses antes do início do projeto, foi realizado treinamento com a equipe de inseminação do quarto sítio sobre a IAPC. Após o treinamento, iniciou-se com cinco coberturas por semana, realizadas de forma pós-cervical. A cada nova semana, eram acrescidas mais cinco coberturas realizadas com IAPC, seguindo dessa forma até chegar às 90 coberturas por semana, realizadas todas de forma pós-cervical.

À medida que manifestavam cio, as fêmeas eram conduzidas para o barracão de gestação, sendo alocadas de forma randômica na linha sequencial de coberturas. Quando o cio era diagnosticado pela manhã (hora zero), a primeira inseminação era realizada à tarde $(12 \mathrm{~h})$, a segunda inseminação no período da manhã seguinte (24h), e a terceira inseminação 48 horas após início do cio. Quando o cio era diagnosticado na parte da tarde (hora zero), a primeira inseminação era realizada no período da manhã seguinte (12h), e as demais inseminações eram feitas com intervalo de 24 horas.

As fêmeas em IAT foram inseminadas na presença do macho e as doses eram depositadas na porção cranial da cérvix por meio de uma pipeta descartável com ponta de espuma (Equittec $^{\circledR}$, Marau, RS, Brasil). As fêmeas em IAPC foram inseminadas sem a presença do macho, e as doses eram depositadas no corpo do útero ou em um dos cornos uterinos, com auxílio de um cateter de polipropileno (Equittec ${ }^{\circledR}$, Marau, RS, Brasil) que deslizava pelo interior da pipeta, inserido até $200 \mathrm{~mm}$ para além da cérvix. 
O diagnóstico de retorno ao cio era efetuado a partir dos 18 dias até os 23 dias após a IA, sendo realizado mediante o reflexo de tolerância ao homem na presença do macho. A confirmação da prenhez era realizada pela ultrassonografia transcutânea em tempo real WED-2000AV ${ }^{\circledR}$ (Bretanha, Passo Fundo, Brasil), contendo fêmeas com 26 a 32 dias de gestação. As fêmeas, depois de confirmada a gestação pelo ultrassom, eram enviadas para as granjas produtoras de leitões.

Os dados de idade das fêmeas, peso, números de cios pré-inseminação e número de doses por IA à cobertura foram coletados no momento da inseminação. $\mathrm{O}$ diagnóstico de gestação, utilizado para o cálculo da taxa de prenhez, foi realizado 26 a 32 dias após a inseminação. Os dados dos partos, referentes ao número dos leitões nascidos (nascidos totais, nascidos vivos, nascidos mortos e mumificados), foram coletados nas granjas por meio do programa de gestão de dados (Pigmaster ${ }^{\circledR}$, Videira, SC, Brasil).

No momento da inseminação e logo após ela, foram avaliados também os seguintes parâmetros: o sucesso na transposição do cateter pela cérvix; a dificuldade no transpasse do cateter pela cérvix, classificada em sim ou não, sendo considerados para sim somente cateteres facilmente introduzidos na primeira tentativa; a ocorrência de sangramento, classificada em sim ou não; e a ocorrência de refluxo, classificada como presente ou ausente. As fêmeas nas quais não foi possível realizar o transpasse da cérvix foram cobertas de forma tradicional, e seus dados reprodutivos não foram contabilizados no experimento.

Foram coletadas 70 amostras de refluxo, sendo 35 amostras da IAT e 35 amostras da IAPC no Tabela 1. Parâmetros zootécnicos de idade, peso, número de cios pré-inseminação, número de doses inseminantes e período de duração da gestação de leitoas submetidas à inseminação artificial tradicional ou à inseminação artificial pós-cervical

\begin{tabular}{lcl}
\hline Variáveis & IAT $(80 \mathrm{~mL})$ & IAPC $(40 \mathrm{~mL})$ \\
$\left(2,5 \times 10^{9} \mathrm{Sptz}\right)$ & $\left(1,5 \times 10^{9} \mathrm{Sptz}\right)$ \\
\hline Idade IA & $235,78 \pm 1,02$ & $235,76 \pm 0,968$ \\
Peso IA & $143,47 \pm 0,580$ & $144,73 \pm 0,595$ \\
$\mathrm{~N}^{\mathbf{o}}$ cios pré-IA & $2,714 \pm 0,03$ & $2,691 \pm 0,03$ \\
$\mathrm{~N}^{\mathbf{o}}$ doses IA & $2,271 \pm 0,04$ & $2,254 \pm 0,04$ \\
Duração gestação & $113,59 \pm 0,32$ & $113,54 \pm 0,23$ \\
\end{tabular}

momento da IA e até 30 minutos após, utilizando bolsas de colostomia descartáveis (Medsonda ${ }^{\circledR}$, Arapoti, PR, Brasil). Os refluxos coletados foram encaminhados à central de inseminação para avaliação da concentração no sistema CASA (Computer-assisted sperm analysis). Foi mensurado o tempo total para a realização da inseminação e também foram coletados dados sobre o custo por fêmea relativo ao método de inseminação para posterior análise financeira comparativa.

As análises estatísticas foram realizadas utilizando-se o sistema de análise estatística $\left(\right.$ Minitab $\left.^{\circledR}\right)$, versão 17.3. As taxas de retorno ao estro e de parto, o percentual de fêmeas com dificuldade na introdução do cateter, a presença de sangue e de refluxo no momento da inseminação e o tempo de duração da inseminação foram analisados pelo teste do quiquadrado. Os parâmetros de tamanho de leitegada de todas as fêmeas que pariram foram submetidos à análise de variância pelo procedimento ANOVA, sendo as médias comparadas pelo teste de Tukey. Os dados sobre total de leitões nascidos e percentual de volume e espermatozoides no refluxo foram submetidos à análise de variância por meio do procedimento ANOVA, com a inclusão dos efeitos fixos do tratamento e as variáveis dos machos e das fêmeas. Diferenças com $\mathrm{P} \leq 0,05$ foram consideradas estatisticamente significantes.

\section{RESULTADOS}

Não houve diferença $(\mathrm{P}>0,05)$ entre os grupos IAT e IAPC quanto aos parâmetros zootécnicos de idade, peso, número de cios pré-inseminação, número de doses inseminantes e período de duração da gestação (Tab. 1). 
A taxa de sucesso no transpasse da cérvix foi de $91,04 \%$ das leitoas submetidas à inseminação artificial pós-cervical (254/279). A dificuldade no transpasse do cateter pela cérvix em pelo menos uma das inseminações foi observada em 41,58\% das fêmeas (116/279). A dificuldade na inserção do cateter não teve influência $(\mathrm{P}>0,05)$ em relação à taxa de parto e ao número de leitões nascidos totais.
A presença de sangramento durante a inseminação foi semelhante nos dois grupos com $18,32 \%(50 / 273)$ e $18,28 \%(51 / 279)$ para a IAT e a IAPC, respectivamente (Tab. 2). A presença de sangramento nas fêmeas durante a inseminação não afetou a taxa de parto e o tamanho de leitegada para ambos os tratamentos.

Tabela 2. Taxa de transpasse, dificuldade no transpasse e presença de sangramento em leitoas submetidas à inseminação artificial tradicional ou à inseminação artificial pós-cervical

\begin{tabular}{|c|c|c|}
\hline Variáveis & $\begin{array}{c}\text { IAT }(80 \mathrm{~mL}) \\
\left(2,5 \times 10^{9} \mathrm{Sptz}\right)\end{array}$ & $\begin{array}{c}\text { IAPC }(40 \mathrm{~mL}) \\
\left(1,5 \times 10^{9} \mathrm{Sptz}\right)\end{array}$ \\
\hline Taxa de transpasse, $\%$ & $*$ & $91,04(254 / 279)$ \\
\hline Dificuldade no transpasse, $\%$ & $*$ & $41,58(116 / 279)$ \\
\hline Presença de sangramento, $\%$ & $18,32(50 / 273)$ & $18,28(51 / 279)$ \\
\hline
\end{tabular}

* Não foi realizada tentativa de transpasse da cérvix na IAT.

A presença de refluxo nas fêmeas foi de $56,04 \%$ e $20,79 \%$ na IAT e na IAPC, respectivamente, e não afetou a taxa de parto nem o tamanho de leitegada para ambos os tratamentos. $\mathrm{O}$ percentual de volume médio refluído foi de $44,58 \%$ e $36,33 \%$ para IAT e IAPC, respectivamente. $\mathrm{O}$ percentual de espermatozoides presentes no refluxo foi maior na IAT $(21,47 \%)$ do que na IAPC $(17,48 \%)$.

O tempo necessário para a realização da IA foi diferente entre os tratamentos: o tempo médio na IAT foi de 4,04 minutos e na IAPC foi de 1,47 minutos, entretanto o número de leitões nascidos totais e a taxa de parto não foram influenciados pelo tempo de duração da inseminação nem pelo tratamento.

Os dois métodos de inseminação (IAT e IAPC) produziram índices reprodutivos semelhantes. Não houve diferença estatística na taxa de retorno ao cio, na taxa de parto, no número de leitões nascidos totais, no número de leitões nascidos vivos, no número de leitões nascidos mortos e no número de leitões mumificados (Tab. 3).

Tabela 3. Performance reprodutiva de leitoas submetidas à inseminação artificial tradicional comparadas com leitoas submetidas à inseminação artificial pós-cervical

\begin{tabular}{lcc}
\multicolumn{1}{c}{ Variáveis } & IAT $(80 \mathrm{~mL})$ & IAPC $(40 \mathrm{~mL})$ \\
& $\left(2,5 \times 10^{9} \mathrm{Sptz}\right)$ & $\left(1,5 \times 10^{9} \mathrm{Sptz}\right)$ \\
\hline Taxa de retorno ao cio, \% & $3,66(010 / 273)$ & $2,15(006 / 279)$ \\
Taxa de parto, \% & $89,38(244 / 273)$ & $91,76(256 / 279)$ \\
$\mathrm{N}^{\mathrm{o}}$ leitões nascidos totais & $11,63 \pm 0,19$ & $11,81 \pm 0,19$ \\
$\mathrm{~N}^{\mathrm{o}}$ leitões nascidos vivos & $10,73 \pm 0,36$ & $10,99 \pm 0,20$ \\
$\mathrm{~N}^{\mathrm{o}}$ leitões nascidos mortos & $0,66 \pm 0,06$ & $0,58 \pm 0,06$ \\
$\mathrm{~N}^{\mathbf{o}}$ leitões mumificados & $0,27 \pm 0,04$ & $0,20 \pm 0,03$ \\
\hline
\end{tabular}

A diferença no custo para cobrir a leitoa utilizando a IAPC é U\$ 4,20 menor quando comparado ao custo para cobrir a mesma leitoa utilizando a IAT. O principal fator que impacta nesse custo é a redução no número de machos utilizados na central de inseminação que o uso da técnica possibilita. Dessa forma, o gasto com a aquisição de machos para reposição é menor, e essa economia é responsável por $95,42 \%$ do total reduzido (Tab. 4). 


\section{Ternus et al.}

Tabela 4. Custos na realização de 320 coberturas mensais em nulíparas suínas submetidas à inseminação artificial tradicional versus inseminação artificial pós-cervical

\begin{tabular}{lccl}
\hline \multicolumn{1}{c}{ Descrição do material } & IAT $(80 \mathrm{~mL})$ & IAPC $(45 \mathrm{~mL})$ & Diferença \\
\hline Diluente curta duração & $\mathrm{U} \$ 80,90$ & $\mathrm{U} \$ 45,51$ & $\mathrm{U} \$ 35,39$ \\
Diluente longa duração & $\mathrm{U} \$ 40,93$ & $\mathrm{U} \$ 23,03$ & $\mathrm{U} \$ 17,90$ \\
Reposição machos & $\mathrm{U} \$ 2.820,40$ & $\mathrm{U} \$ 1.538,40$ & $\mathrm{U} \$ 1.282,00$ \\
Ração machos & $\mathrm{U} \$ 169,85$ & $\mathrm{U} \$ 92,65$ & $\mathrm{U} \$ 77,20$ \\
Pipeta & $\mathrm{U} \$ 81,23$ & $\mathrm{U} \$ 81,23$ & $\mathrm{U} \$ 0,00$ \\
Cateter & $\mathrm{U} \$ 0,00$ & $\mathrm{U} \$ 69,04$ & $-\mathrm{U} \$ 69,04$ \\
\hline Total / mês & & & $\mathrm{U} \$ 1.343,45$ \\
Total / ano & & & $\mathrm{U} \$ 16.121,53$ \\
\hline *Cotação Dólar $(19 / 05 / 16)-\mathrm{R} \$ 3,5771$ & & &
\end{tabular}

*Cotação Dólar (19/05/16) - R\$ 3,5771.

\section{DISCUSSÃO}

Neste estudo, os animais utilizados nos dois grupos experimentais tiveram um alto grau de homogeneidade, apresentando parâmetros zootécnicos muito semelhantes. As nulíparas tiveram idade à cobertura de 235,76 dias e 235,78 dias, peso de $143,4 \mathrm{~kg}$ e $144,7 \mathrm{~kg}$, números de cios de 2,71 e 2,69, entre as diferentes técnicas de inseminação utilizadas, IAT e IAPC, respectivamente, não sendo encontrada diferença estatística. Essa similaridade é importante, pois auxilia no bloqueio de diferentes fatores que possam interferir no resultado.

Os resultados deste trabalho, realizado com nulíparas, mostram que não foi encontrada diferença estatística para os parâmetros taxa de retorno ao cio, taxa de parição, número de leitões nascido totais, quando se compara a técnica de IAT com a de IAPC, o que corrobora os resultados obtidos por Dallanora et al. (2004) e Hernández-Caravaca et al. (2012), utilizando multíparas, e Sbardella et al. (2014), utilizando primíparas. Tais resultados reforçam, mais uma vez, que a IAPC, indiferentemente da categoria animal utilizada, não compromete a performance reprodutiva das fêmeas.

Em estudo utilizando primíparas, Sbardela et al. (2014) conseguiram transpasse da cérvix em $86,40 \%$ das fêmeas inseminadas. O índice obtido no presente estudo, utilizando somente nulíparas, foi de $91,04 \%(254 / 279)$ e assemelha-se ao encontrado em trabalhos com fêmeas multíparas em que o sucesso no transpasse da cérvix foi superior a 90\% (Dallanora et al., 2004; Bennemann et al., 2005; Serret et al., 2005; Diehl et al., 2006). Acredita-se que essa diferença em relação ao sucesso no transpasse da cérvix das nulíparas esteja relacionada à habilidade do operador na realização da IA e também ao tipo de equipamento utilizado na IA.

Os resultados obtidos neste trabalho em relação à taxa de transpasse da cérvix das nulíparas contradizem a recomendação feita por Levis et al. (2001) e Dallanora et al. (2004) de não se utilizar a IAPC nessa categoria de fêmeas. O presente trabalho corrobora o de Sonderman (2016), o qual infere que a IAPC pode ser realizada com sucesso em nulíparas, desde que estas tenham à cobertura pelo menos um cio póspúbere e pelo menos $136 \mathrm{~kg}$. Acredita-se que muito se aprendeu em relação ao manejo da IAPC com o passar dos últimos anos e que muito se evoluiu em relação ao desenvolvimento de novos produtos, facilitando a realização da técnica.

A dificuldade no transpasse do cateter encontrada no trabalho de Martinez et al. (2001), os quais utilizaram fêmeas de ordem de parto 26, foi de $8 \%$. Em estudo em que usaram fêmeas com ordem de parto 1-9, Diehl et al. (2006) encontraram dificuldade em ambos os tratamentos de $27,3 \%$ e $30,6 \%$. No trabalho de Sbardella et al. (2014), utilizando somente primíparas, a dificuldade no transpasse da cérvix foi de $38,3 \%$, dado que se assemelha ao encontrado no presente estudo com nulíparas, que foi de 41,58\% das fêmeas (116/279). Essas dificuldades podem ser explicadas pelo fato de que nulíparas e primíparas apresentam um menor desenvolvimento do trato reprodutivo quando comparadas às multíparas (Sonderman, 2016), justificando, assim, a maior dificuldade para o inseminador conseguir realizar o transpasse da cérvix. 
Nos trabalhos realizados com IAPC utilizando fêmeas multíparas, Dallanora et al. (2004) e Bennemann et al. (2005) encontraram percentual de sangramento em $9,5 \%$ e $8,4 \%$ das fêmeas, respectivamente. Diehl et al. (2006) observaram sangramento em $20,6 \%$ das fêmeas. Essa diferença pode ser explicada pelo uso de algumas fêmeas primíparas no experimento, corroborando os $23,03 \%$ de fêmeas com sangramento encontrados por Sbardella et al. (2014), e estes dados se assemelham aos $18,28 \%$ encontrados no presente estudo.

A maior ocorrência de sangramento após a inseminação, encontrados em primíparas e nulíparas, acredita-se que possa ser justificada em razão de que essas fêmeas ainda não teriam completado o pleno desenvolvimento do trato reprodutivo (Serret et al., 2005), sendo mais provável, dessa forma, que aconteçam com maior facilidade lesões traumáticas, consequentemente aumentando a presença de sangramento após a inseminação (Watson e Behan, 2002). O desempenho reprodutivo nem sempre é afetado quando ocorre sangramento durante a inseminação, conforme constatado no presente estudo, o que corrobora os trabalhos de Benneman et al. (2005) e Serret et al. (2005).

A presença de refluxo nas fêmeas neste trabalho não causou redução no tamanho da leitegada, em consonância com Steverink et al. (1998), Dallanora et al. (2004), Serret et al. (2005) e Sbardella et al. (2014). Acredita-se que a ocorrência de refluxo é aparentemente um processo fisiológico normal na inseminação artificial em suínos, e não está relacionada com uma redução na performance reprodutiva (Steverink et al., 1998).

Entre os ganhos econômicos com a substituição da IAT pela IAPC no presente experimento, o valor mais impactante encontrado foi a redução no custo com aquisição de machos doadores para as centrais de inseminação. A economia por fêmea com a substituição da IAT pela IAPC em leitoas foi de U\$ 4,20. Com um plantel de 400 mil fêmeas, considerando $45 \%$ de reposição anual do plantel, tem-se uma entrada de 180.000 leitoas no ano, o que traz uma oportunidade de economia anual de U\$ 755.697,06. Essa economia financeira mostra a enorme importância do presente estudo, estando alinhado com as premissas da suinocultura atual, a qual busca, de modo incessante, a maximização dos resultados zootécnicos, concomitantemente à redução potencial nos custos de produção.

\section{CONCLUSÕES}

A inseminação artificial pós-cervical em leitoas, realizada com doses inseminantes contendo 1,5 x $10^{9}$ células espermáticas, permite desempenho reprodutivo semelhante ao observado com a inseminação artificial tradicional, realizada com doses inseminantes contendo 2,5 x $10^{9}$ células espermáticas. A presença de sangramento e de refluxo não influenciou a taxa de parto nem o número de leitões nascidos totais em ambos os grupos. É possível realizar a inseminação artificial pós-cervical (IAPC) em leitoas sem redução na performance reprodutiva do rebanho.

\section{AGRADECIMENTOS}

À BRF/SA, especialmente a todo o time da unidade de Videira, ao Centro de Ciências Agroveterinárias - CAV - da Universidade do Estado de Santa Catarina - UDESC - pela oportunidade e suporte na realização deste projeto e à FAPESC pelo apoio aos grupos de pesquisa do CAV/UDESC.

\section{REFERÊNCIAS}

BENNEMANN, P.E.; KOLLER, F.L.; BERNARDI, M.L. et al. Desempenho reprodutivo de fêmeas suínas submetidas à inseminação artificial intra-uterina ou à tradicional. Ciênc. Rural, v.37, p.1735-1739, 2005.

BORTOLOZZO, F.P.; GOLDBERG, A.M.G.; WENTZ, I. Até onde é possível reduzir o número de espermatozoides empregados na inseminação artificial intracervical em suínos sem comprometer a fertilidade? Acta Sci. Vet., v.36, p.17-26, 2008.

BORTOLOZZO, F.P.; WENTZ, I. Manejo reprodutivo da fêmea suína de reposição. Hora Vet., n.110, p.47-54, 1999.

BRANDT, G. Quarto Sítio seria a melhor solução para incorporação de matrizes de reposição em um rebanho suíno? Acta Sci. Vet., v.36, p.137-142, 2008. 
DALLANORA, D.; MEZALIRA, A.; KATZER, L.H. et al. Desempenho reprodutivo de fêmeas suínas inseminadas pela técnica intra-uterina ou tradicional. Pesqui. Agropec. Bras., v.39, p.815819, 2004.

DIEHL， G.N.; AMARAL FILHA, W.S.; KUMMER, R. et al. Nova pipeta para inseminação intra-uterina em suínos. Ciênc. Rural, v.36, p.179-185, 2006.

HANCOCK J.L. Pig insemination technique. Vet. Rec., v.71, p527, 1959.

HERNANDEZ-CARAVACA, I.H.; RICO, M.J.; CARMEN, M. et al. Reproductive performance and backflow study in cervical and post-cervical artificial insemination in sows. Anim. Reprod. Sci., v.136, p.14-22, 2012.

LEVIS, D.G.; BURROUGHS, S.; WILLIAMS, S. "Use of intra-uterine insemination of pigs: pros, cons \& economics" faculty papers and publications in animal science. Paper 618. 2001. Available in: $<$ http://digitalcommons.unl.edu/animalscifacpub/ 618> Accessed in: set. 2015.

MARTINEZ, E.A.; VAZQUEZ, J.M.; ROCA, J. et al. Successful nonsurgical deep intrauterine insemination with small numbers of spermatozoa in sows. Reproduction, v.122, p.289-296, 2001.

ROSTAGNO, H.S.; ALBINO, L.F.T.; DONZELE, J.L. et al. Tabelas brasileiras para aves e suínos: composição de alimentos e exigências nutricionais. Viçosa: UFV, 2005. p. 184

SBARDELLA, P.E.; ULGUIM, R.R.; FONTANA, D.L. et al. The post-cervical insemination does not impair the reproductive performance of primiparous sows. Reprod. Domest. Anim., v.49, p.59-64, 2014.
SCHEID, I.R. Comercial swine artificial in Brazil: development and current use. In: INTERNATIONAL CONFERENCE ON BOAR SEMEN PRESERVATION, 2., 1991, Berlin. Proceedings... Berlin: Embrapa, 1991. v.2, p.299-302. 1991.

SERRET, C.G.; ALVARENGA, M.V.F.D.; CÓRIA, A.L.P. et al. Intrauterine artificial insemination of swine with different sperm concentrations, parities, and methods for prediction of ovulation. Anim. Reprod., v.2, p.250-256, 2005.

SONDERMAN, J.P. The advantages of postcervical insemination (PCAI) on a sow farm. In: 47th AMERICAN ASSOCIATION OF SWINE VETERINARIANS ANNUAL MEETING, 47., 2016. New Orleans. Proceedings... New Orleans: AASV, 2016. p.3-5, 2016.

STEVERINK, D.W.; SOEDE, N.M.; BOUWMAN, E.G.; KEMP, B. Semen backflow after insemination and its effect on fertilization results in sows. Anim. Reprod. Sci., v.54, p.109119, 1998.

WATSON, P.F.; BEHAN, J.R. Intrauterine insemination of sows with reduced sperm numbers: results of a commercially based field trial. Theriogenology, v.57, p.1683-1693, 2002.

WENTZ, I.; VARGAS, A.J.; BORTOLOZZO, F.P.; CASTAGNA C.D. Situação atual da inseminação artificial em suínos no Brasil e viabilização econômica do emprego desta biotécnica. In: SIMPÓSIO INTERNACIONAL DE INSEMINAÇÃO ARTIFICIAL EM SUÍNOS, 3., 2000, Flores da Cunha. Anais... Flores da Cunha, [s.n.], 2000. p.5-12. 